\title{
Response and participation of underserved populations after a three-step invitation strategy for a cardiometabolic health check
}

Iris Groenenberg 1*, Mathilde R. Crone ${ }^{1}$, Sandra van Dijk1, Jamila Ben Meftah¹, Barend J. C. Middelkoop', Willem J. J. Assendelft ${ }^{1,2}$ and Anne M. Stiggelbout ${ }^{3}$

\begin{abstract}
Background: Ethnic minority and native Dutch groups with a low socioeconomic status (SES) are underrepresented in cardiometabolic health checks, despite being at higher risk. We investigated response and participation rates using three consecutive inexpensive-to-costly culturally adapted invitation steps for a health risk assessment (HRA) and further testing of high-risk individuals during prevention consultations (PC).

Methods: A total of 1690 non-Western immigrants and native Dutch with a low SES (35-70 years) from six GP practices were eligible for participation. We used a 'funnelled' invitation design comprising three increasingly cost-intensive steps: (1) all patients received a postal invitation; (2) postal non-responders were approached by telephone; (3) final nonresponders were approached face-to-face by their GP. The effect of ethnicity, ethnic mix of GP practice, and patient characteristics (gender, age, SES) on response and participation were assessed by means of logistic regression analyses.

Results: Overall response was $70 \%(n=1152)$, of whom $62 \%(n=712)$ participated in the HRA. This was primarily accomplished through the postal and telephone invitations. Participants from GP practices in the most deprived neighbourhoods had the lowest response and HRA participation rates. Of the HRA participants, $29 \%(n=207)$ were considered high-risk, of whom $59 \%(n=123)$ participated in the PC. PC participation was lowest among native Dutch with a low SES.
\end{abstract}

Conclusions: Underserved populations can be reached by a low-cost culturally adapted postal approach with a reminder and follow-up telephone calls. The added value of the more expensive face-to-face invitation was negligible. PC participation rates were acceptable. Efforts should be particularly targeted at practices in the most deprived areas.

\section{Background}

Cardiometabolic disease (CMD), namely cardiovascular disease (CVD), diabetes mellitus (DM), and kidney failure, is a leading cause of death in high-income countries [1]. CMD risk is related to low socioeconomic status (SES) and a non-Western origin $[2,3]$. In The Netherlands, CVD prevalence and mortality are particularly high among Surinamese and Turkish people $[4,5]$. Turkish, Moroccans, and especially Hindustani Surinamese have a higher DM risk [6]. As CMD is largely preventable, focus has shifted towards primary prevention among high-risk individuals

\footnotetext{
* Correspondence: i.groenenberg@lumc.nl

'Department of Public Health and Primary Care, Leiden University Medical Center, Hippocratespad 21, PO Box 9600, V0-P, 2300 RC, Leiden, The Netherlands

Full list of author information is available at the end of the article
}

and, as a result, health checks have been implemented in various countries [7-9]. A non-Western origin and a low SES are associated with lower health check attendance [10]. This selective non-attendance contributes to inequalities in health gains from screening. Efforts to increase participation of these underserved (difficult-to-reach, high-risk) populations are therefore relevant, and a prerequisite for cost-effectiveness [11, 12].

Attempts to increase participation in health checks in the general population usually compared postal, telephone, and face-to-face strategies in parallel [13-17]. In general, a postal invitation combined with telephone reminders was most effective in cancer screening attendance [14]. However, studies taking ethnicity or SES into account tend to find the more labour-intensive, expensive face-toface strategies or combinations of strategies, to be most 
effective [13, 15-17]. In The Netherlands, only this 'casefinding' approach is currently reimbursed by basic health insurance [18]. Nevertheless, a strategy with a sequential inexpensive-to-costly 'funnel' invitation procedure might be more cost-effective. We investigated response and participation in a health check by using such a funnel design that encompassed three consecutive culturally targeted and personalised invitation steps: first, a postal invitation to eligible individuals, second, a telephone invitation for postal non-responders, third, a face-to-face invitation for telephone non-responders. We assessed both response and participation, with response referring to the patient's awareness of the screening and providing a response as to whether or not (s)he intended to participate, and participation to actual participation in the health check.

Another way of increasing cost-effectiveness entails using a two-stage health check approach, which usually refers to employing a non-invasive and low-cost risk stratification tool for all individuals, followed by more expensive biometric and blood testing for high-risk individuals [12, 19]. The Dutch cardiometabolic health check follows such a twostage approach. Stage one comprises a short health risk assessment (HRA) consisting of six risk factor questions [20, 21] for people aged 45-70 years. Patients have to calculate their own HRA risk score. In case of an increased risk according to the HRA, patients are advised to attend a prevention consultation (PC) at the GP (stage two). However, in the general population it has been shown that patients then refrain from participation on two separate occasions (HRA and PC), possibly leading to even higher nonparticipation rates among underserved populations [22]. Therefore, we examined HRA participation and subsequent PC participation after receiving an increased HRA risk score, as well as the effect of ethnicity, ethnic mix of GP practice, and patient characteristics (gender, age, SES) on participation.

Summarizing, our research questions were:

1. What are response and participation rates among different underserved populations after a postal invitation to complete the HRA?

2. To what extent can response and HRA participation among postal non-responders from the different groups be increased by telephone and by a subsequent face-toface invitation by the GP among remaining nonresponders?

3. What proportion of high-risk HRA participants attends the PC, and does this vary between different underserved populations and invitation steps?

\section{Methods}

\section{Study population and setting}

Between May 2012 and December 2013, patients from six general practices in deprived neighbourhoods in the
Netherlands were invited for the cardiometabolic health check. Patients had to be Turkish, Moroccan, or Surinamese, or native Dutch with a low SES. As ethnicity is not registered by the GP, ethnic origin was deduced from family name, after which the classification was checked by the GP. He/she also selected the native Dutch patients with a low SES. The SES status was then corroborated by a neighbourhood SES score. A low SES score represents a low neighbourhood social status and consists of the average income and the proportion of low-income, low-educated, and unemployed individuals [23]. Patients had to be 45-70 years old. The lower age limit for the Hindustani Surinamese was 35 years because of their genetically increased risk of DM. Exclusion criteria were having (had) CMD, use of antihypertensive/lipid-lowering drugs, or having a complete cardiometabolic risk profile within the previous year (see Additional file 1).

Ethical approval was obtained from the Medical Ethics Committee of the Leiden University Medical Centre. Participation in the study followed an 'opt-out procedure': patients could sign a reply card declining participation.

\section{Three-step invitation strategy for stage one: HRA participation}

The HRA consisted of six short questions on age, smoking status, BMI, waist circumference, and family history of CVD or DM. Three culturally targeted and personalised invitation steps for the HRA were tested following a funnel design.

Step one: eligible patients were invited by a personalised, GP-signed letter. Enclosed were the HRA and an information brochure (both with ethnic specific pictures), a tape measure for measuring waist circumference, a reply card declining participation, and a stamped return envelope addressed to the GP. The formulation was simplified to fit the generally lower health literacy levels of our target population. Turkish and Moroccan patients received Turkish or Arabic versions, respectively, in addition to the Dutch materials. After two weeks of non-response, patients received a reminder package. A detailed description of the (cultural) adaptations made in the invitation, HRA, and information brochure can be found in Additional file 2. Step two: after another two weeks of non-response, patients were called by a trained research assistant on behalf of the GP. Turkish and Moroccan patients were called by Turkish, Arabic, and Berber (which is an oral only language) speaking research assistants. The conversation was structured by a script supporting patients in making an informed decision about (non-)participation. When a participant decided to participate, the HRA was immediately completed by telephone and the HRA risk score was 
calculated by the research assistant. The national telephone directory was consulted when telephone numbers were missing, unlisted, or inoperative. Patients were approached with a maximum of four call attempts. Step three: after four failed call attempts, patients were invited face-to-face when visiting their GP for an unrelated consultation. GPs received a pop-up in the electronic patient file of a non-responding patient. The GPs followed a short version of the telephone script to help patients make an informed decision about (non-)participation. When a participant decided to participate, the HRA was immediately completed at the GP practice and the HRA risk score was calculated by the practice nurse. The faceto-face invitation period lasted six months, which was deemed long enough since ethnic minorities and native Dutch patients with a low SES are known to consult the GP up to once or twice a month [24, 25]. If patients had not visited the practice within this period, they were classified as final non-responders.

\section{Stage two: PC participation among high-risk individuals}

Participants had to calculate their own HRA risk score. Participants with a low risk score were referred to the Dutch health check website where advice for maintaining or improving their lifestyle was provided. Participants with a high-risk score were advised to attend the PC. This advice was provided either written, by phone, or face-to-face, depending on the relevant invitation step. Patients themselves were responsible for making an appointment with the GP. During the first $\mathrm{PC}$, the biometric HRA measures were checked (weight, height, and blood pressure) and lab work on fasting glucose and cholesterol levels was completed. During the second PC, the results were discussed, the cardiometabolic risk profile was drawn, lifestyle advice was provided, and medication was prescribed if necessary [26]. Because we only looked at participation in the first consultation, we refer to both consultations as one ('PC participation').

\section{Measures}

The main outcome measures were response, HRA participation, and PC participation. The secondary outcome measure was HRA risk score.

Response was defined as 'yes' if an individual provided a reaction as to whether he/she wanted to participate in the HRA or not and 'no' if an individual did not respond at all. It was calculated as a percentage of all patients. Telephone response was calculated as the proportion of postal non-responders, who picked up the phone and indicated an intention to participate or not. Finally, face-

Table 1 Sociodemographic characteristics of all patients eligible for the cardiometabolic health check

\begin{tabular}{|c|c|c|c|c|c|c|c|c|c|c|c|c|c|c|c|c|}
\hline & \multicolumn{3}{|c|}{ Total $(n=1644)$} & \multicolumn{3}{|c|}{$\begin{array}{l}\text { Dutch with low SES } \\
(n=437)\end{array}$} & \multicolumn{3}{|c|}{$\begin{array}{l}\text { Turkish } \\
(n=353)\end{array}$} & \multicolumn{3}{|c|}{$\begin{array}{l}\text { Moroccan } \\
(n=344)\end{array}$} & \multicolumn{3}{|c|}{$\begin{array}{l}\text { Surinamese } \\
(n=510)\end{array}$} & \multirow[b]{2}{*}{$p$ value } \\
\hline & $\bar{n}$ & $\%$ & mean (SD) & $\bar{n}$ & $\%$ & mean (SD) & $\bar{n}$ & $\%$ & $\overline{\text { mean }(\mathrm{SD})}$ & $\bar{n}$ & $\%$ & $\overline{\text { mean }(\mathrm{SD})}$ & $\bar{n}$ & $\%$ & $\frac{\text { mean }(S D)}{}$ & \\
\hline \multicolumn{17}{|l|}{ Gender } \\
\hline Male & 882 & 54 & & 220 & 50 & & 192 & 54 & & 210 & $61^{a}$ & & 260 & 51 & & .011 \\
\hline Female & 762 & 46 & & 217 & 50 & & 161 & 46 & & 134 & 39 & & 250 & 49 & & \\
\hline Age (years) & 1644 & 100 & $50(7.00)$ & 437 & 100 & $52(6.27)^{b}$ & 353 & 100 & $51(5.55)$ & 344 & 100 & $51(6.32)$ & 510 & 100 & $47(7.57)^{c}$ & $<.001$ \\
\hline \multicolumn{17}{|l|}{ Age (cat.) } \\
\hline $35-45$ & 259 & 16 & & 14 & 3 & & 8 & 2 & & 15 & 4 & & 222 & 44 & & \\
\hline $45-50$ & 595 & 36 & & 160 & 37 & & 164 & 46 & & 147 & 43 & & 124 & 24 & & \\
\hline $50-55$ & 392 & 24 & & 118 & 27 & & 97 & 27 & & 93 & 27 & & 84 & 16 & & \\
\hline $55-60$ & 213 & 13 & & 75 & 17 & & 48 & 14 & & 44 & 13 & & 46 & 9 & & \\
\hline $60-65$ & 120 & 7 & & 45 & 10 & & 26 & 7 & & 27 & 8 & & 22 & 4 & & \\
\hline $65+$ & 65 & 4 & & 25 & 6 & & 10 & 3 & & 18 & 5 & & 12 & 2 & & \\
\hline SES score (score) & 1644 & 100 & $-2.14(2.46)$ & 437 & 100 & $-0.39(1.55)$ & 353 & 100 & $-3.32(2.28)$ & 344 & 100 & $-2.30(2.43)$ & 510 & 100 & $-2.73(2.43)$ & $<.001^{d}$ \\
\hline \multicolumn{17}{|l|}{ SES score (cat.) } \\
\hline$>0$ & 470 & 29 & & 231 & 53 & & 48 & 14 & & 82 & 24 & & 109 & 21 & & \\
\hline 0 till -2 & 386 & 24 & & 151 & 35 & & 57 & 16 & & 91 & 26 & & 87 & 17 & & \\
\hline-2 till -4 & 267 & 16 & & 34 & 8 & & 66 & 19 & & 52 & 15 & & 115 & 23 & & \\
\hline$<-4$ & 521 & 32 & & 21 & 5 & & 182 & 52 & & 119 & 35 & & 199 & 39 & & \\
\hline
\end{tabular}

${ }^{a}$ Significantly more males than females when compared to the native Dutch and Surinamese

${ }^{\mathrm{b}}$ Significantly older than the other ethnic groups

'Significantly younger than the other ethnic groups

${ }^{d}$ All ethnic groups differed significantly from each other 
to-face response was calculated as the proportion of telephone non-responders, who were approached faceto-face by their GP and indicated an intention to participate or not. Additionally, to take into account the fact that not all patients visited their GP for an unrelated consultation in the research period, face-to-face response was also calculated as a percentage of those telephone nonresponders who actually visited their GP.

HRA participation was defined as 'yes' if the HRA was completed and 'no' if the HRA was not completed. It was calculated as the proportion of responders of each specific invitation step.

HRA risk score was defined as low or high risk and was calculated as the proportion of HRA participants.

$P C$ participation was defined as 'yes' if the $\mathrm{PC}$ was attended when having a high-risk HRA score and 'no' if the PC was not attended. It was calculated as the proportion of individuals with a high-risk HRA score.

\section{Covariates}

Patient characteristics were: ethnicity (native Dutch/ Turkish/Moroccan/Surinamese), gender (male/female), age (30-45/45-50/50-55/55-60/60-65/65+ years), and neighbourhood SES score $(>0 / 0$ till $-2 /-2$ till $-4 /<-4)$. A low SES score equals a low SES. The average SES score in the Netherlands in 2010 was 0.17 (-7.25 till 3.19), whereas in our study it was -2.14 (-6.23 till 2.88) [23]. The ethnic mix of GP practice variable was divided in three groups: predominantly non-Western patient population, approximately equal combination, and predominantly native Dutch with a low SES patient population. Invitation steps were: mail, phone, and face-to-face.

\section{Data analysis}

Descriptive analyses were applied to describe the patient population. Differences in patient characteristics between the ethnic groups were assessed by means of ANOVA. Univariate logistic regression was used to assess whether patient characteristics were or ethnic mix of GP practice was related to response and participation rates. Odds ratios (ORs) regarding the influence of ethnicity on outcome measures were corrected for relevant covariates $(p$-value $<0.05)$ by means of multivariate logistic regression. As the populations who responded to the various invitation steps logically differed, results were stratified by invitation step.

\section{Results}

\section{Demographics}

Of the 1690 individuals eligible for invitation, 43 had an unknown or wrongly classified ethnicity, two had started antihypertensives right before start of the study, and one had missing contact details. Exclusion from analyses resulted in 1644 eligible individuals. Slightly more males
(54\%) than females (46\%) were invited (Table 1). The Moroccan group consisted of more males than the native Dutch and Surinamese groups. Participants were on average 50 years old. The native Dutch were older and the Surinamese were younger than the other ethnic groups. The native Dutch and the Turkish had a higher and a lower SES score than the other ethnic groups, respectively.

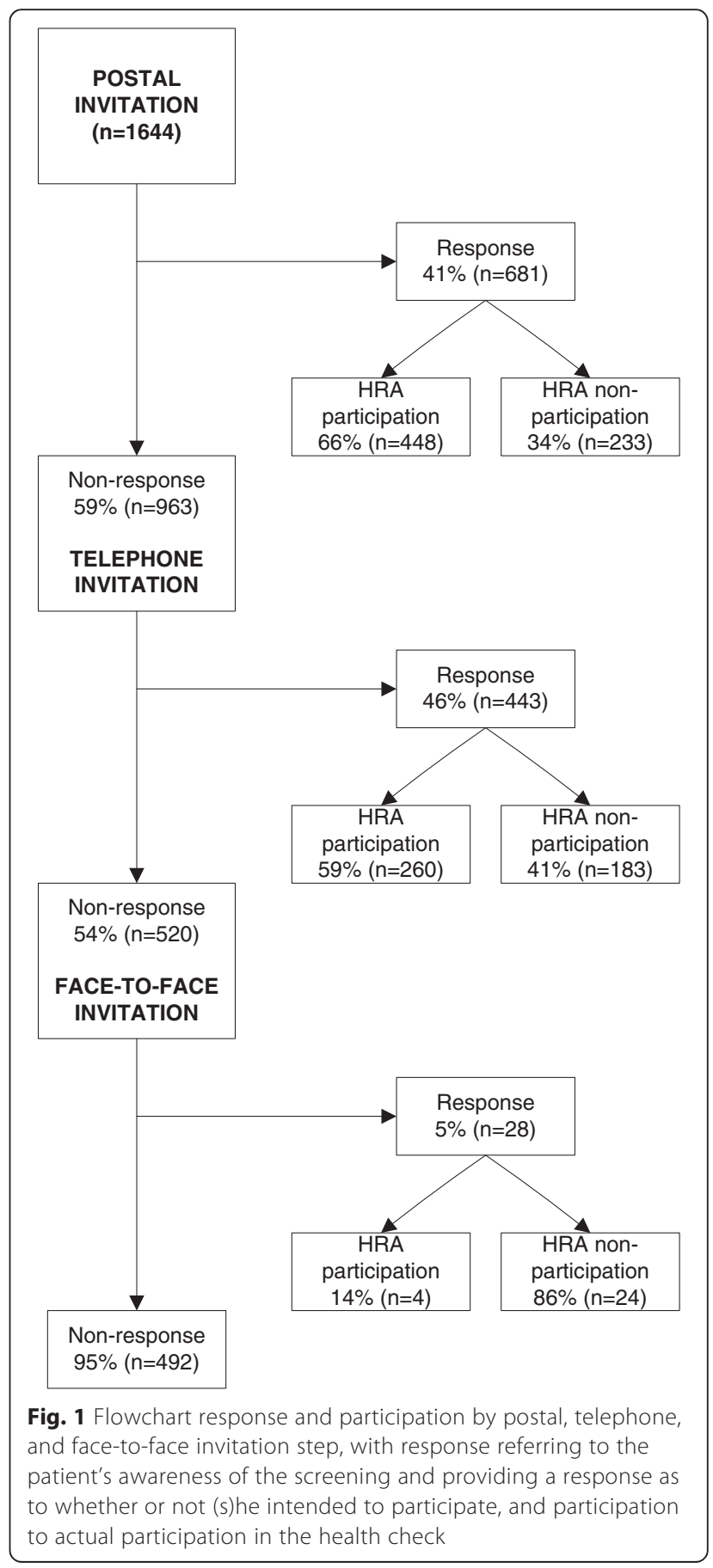




\section{Response}

Total response (those who indicated an intention to participate or not) was $70 \%(n=1152)$ of our underserved populations (Fig. 1). Of all individuals invited, $41 \%(n=681)$ responded to the postal invitation (Table 2). Of the postal non-responders, $46 \%(n=443)$ responded by telephone. Finally, of all telephone nonresponders, $5 \%(n=28)$ responded face-to-face. When we only considered those non-responders who attended their GP for an unrelated consultation during the research period of 6 months $(n=225)$, response was $12 \%$. Face-toface results are not presented in the tables as numbers were too small. A comparison between (postal or telephone) responders $(n=1125)$ and non-responders $(n=520)$ revealed that those left over for face-to-face recruitment were more often men $(p \leq 0.001)$ and individuals with a low SES score $(p \leq 0.001)$.

The higher odds of response among native Dutch groups disappeared when adjusting for relevant covariates. This was mainly explained by differences regarding ethnic mix of GP practice (Table 3). The native Dutch in predominantly non-Western practices did not respond more often than the other ethnic groups, and even significantly less than the Turkish (OR 0.52, 95 \% CI 0.31$0.88, p=0.014)$. Additionally, response was higher for all ethnic groups in the mixed and predominantly native Dutch practices when compared to the predominantly non-Western practices (Table 2).

Table 2 Response in postal and telephone steps

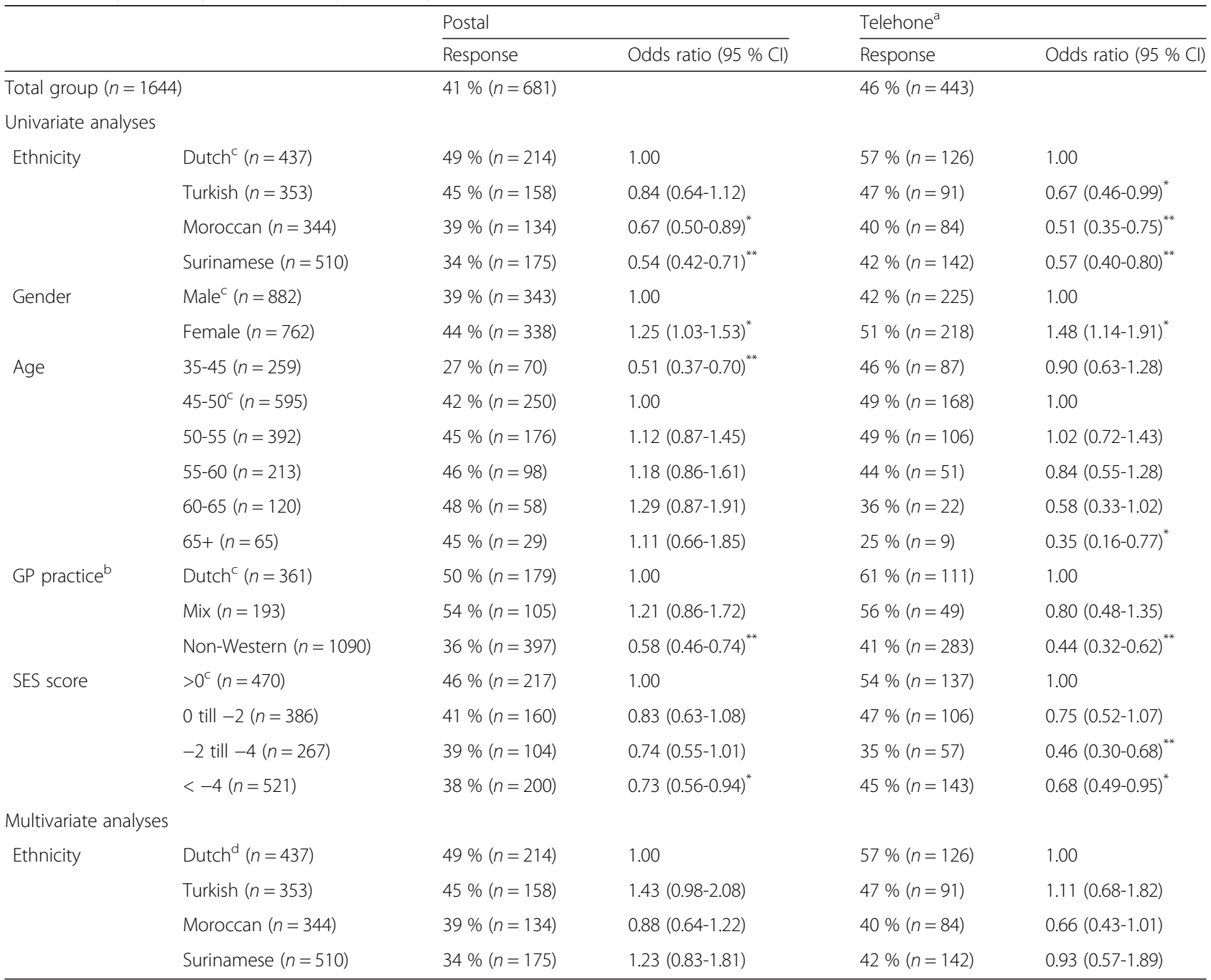

${ }^{a}$ As percentage of postal non-responders

${ }^{b}$ Predominant composition of patient population

${ }^{c}$ Reference category univariate analyses

${ }_{*}^{\mathrm{d}}$ Reference category multivariate analyses, corrected for relevant variables (gender, age, ethnic mix of GP practice, and/or SES score) * $p<0.05$

${ }^{* *} p<0.001$ 
Table 3 Response and HRA participation, stratified by GP practice and ethnicity

\begin{tabular}{|c|c|c|c|c|}
\hline GP practice & Ethnicity & $\%(n)$ & Response, \% $\%^{a}(n)$ & HRA participation, $\%^{\mathrm{b}}(\mathrm{n})$ \\
\hline \multirow[t]{5}{*}{ Dutch low SES $(n=362)$} & Dutch & $74 \%(n=270)$ & $82 \%(n=221)$ & $70 \%(n=154)$ \\
\hline & Turkish & $3 \%(n=10)$ & $80 \%(n=8)$ & $63 \%(n=5)$ \\
\hline & Moroccan & $21 \%(n=75)$ & $80 \%(n=60)$ & $60 \%(n=36)$ \\
\hline & Surinamese & $2 \%(n=7)$ & $86 \%(n=6)$ & $50 \%(n=3)$ \\
\hline & Total & $100 \%(n=362)$ & $81 \%(n=295)$ & $67 \%(n=198)$ \\
\hline \multirow[t]{5}{*}{$\operatorname{Mix}(n=194)$} & Dutch & $49 \%(n=95)$ & $88 \%(n=84)$ & $64 \%(n=54)$ \\
\hline & Turkish & $9 \%(n=18)$ & $83 \%(n=15)$ & $53 \%(n=8)$ \\
\hline & Moroccan & $39 \%(n=76)$ & $74 \%(n=56)$ & $66 \%(n=37)$ \\
\hline & Surinamese & $3 \%(n=5)$ & $80 \%(n=4)$ & $100 \%(n=4)$ \\
\hline & Total & $100 \%(n=194)$ & $82 \%(n=159)$ & $65 \%(n=103)$ \\
\hline \multirow[t]{5}{*}{ Non-Western $(n=1091)$} & Dutch & $6 \%(n=73)$ & $58 \%(n=42)$ & $57 \%(n=24)$ \\
\hline & Turkish & $30 \%(n=325)$ & $72 \%(n=235)$ & $58 \%(n=137)$ \\
\hline & Moroccan & $18 \%(n=194)$ & $55 \%(n=106)$ & $56 \%(n=59)$ \\
\hline & Surinamese & $46 \%(n=499)$ & $63 \%(n=315)$ & $61 \%(n=193)$ \\
\hline & Total & $100 \%(n=1091)$ & $64 \%(n=698)$ & $59 \%(n=413)$ \\
\hline
\end{tabular}

${ }^{a}$ As percentage of the entire ethnic group

${ }^{b}$ As percentage of responders

\section{Stage one: HRA participation}

Of the 1152 responders, $62 \%(n=712)$ participated in the HRA (Table 4). Participation rates among postal responders $(n=448,66 \%)$ were comparable to those among telephone responders $(n=260,59 \%)$. The participation rate of face-to-face responders was only $14 \%$ $(n=4)$. Just as with response, the ethnic differences in HRA participation disappeared when adjusting for relevant covariates, in particular ethnic mix of GP practice. In the predominantly native Dutch practices, the native Dutch patients participated more often in the HRA than the nonWestern patients (Table 3). However, in the predominantly non-Western and mixed practices, the native Dutch had comparable or lower HRA participation rates than the other ethnic groups (not significant).

\section{Stage two: HRA risk result and PC participation}

Of the HRA participants, $29 \%(n=207)$ had a high-risk result (Table 5). When correcting for relevant covariates, the significantly lower risk score of Surinamese participants disappeared. This was mainly explained by age differences between groups. For Hindustani Surinamese, the age threshold to be invited for the HRA was lower due to their genetic higher risk of DM. The risk formula, however, was not adjusted for this heightened risk.

Of the high-risk individuals, $59 \%(n=123)$ participated in the PC. All non-Western groups had higher odds of PC participation when compared to the native Dutch. We found no differences in risk score and in PC participation between the postal versus the telephone step.

\section{Discussion}

\section{Strengths and weaknesses}

We developed materials matching the (cultural) preferences of underserved populations facilitating response and HRA participation possibilities. These adjustments were based on information derived from the literature and the results of focus groups [27]. This approach, combined with the funnelled invitation design, gave as many individuals as possible the opportunity to make an informed decision about participation, acknowledged previously to be important but difficult to measure [28, 29]. With the fast rise of individuals having access to internet we considered using the current online HRA, but after careful deliberation with the populations under study decided it would be fruitless [30]. The pragmatic stepwise invitation approach is most feasible to implement in practice and has the greatest potential of being cost-effective. However, we cannot conclude which invitation step is most effective and, therefore, results are difficult to compare with others usually comparing strategies in parallel. Second, we did not receive a response of $30 \%$ of the patients. In the scope of reducing health inequalities, it is important to reach precisely those individuals about whom we have no health risk information at all, to find out whether our responders are the groups at highest risk. Third, the HRA was completed by participants themselves, possibly leading to reporting errors and mistakes in calculating one's risk score. Fourth, the telephone calls were performed by research assistants, not the GP practice nurse. The average duration of these calls was nine minutes, however, this included the time necessary to ask some additional questions needed for the study. Approximately six minutes were used 
Table 4 Participation rates of responders to postal and telephone steps

\begin{tabular}{|c|c|c|c|c|c|}
\hline & & \multicolumn{2}{|c|}{ Postal (response $n=681$ ) } & \multicolumn{2}{|c|}{ Telephone (response $n=443$ ) } \\
\hline & & Participation & Odds ratio $(95 \% \mathrm{Cl})$ & Participation & Odds ratio $(95 \% \mathrm{Cl})$ \\
\hline \multicolumn{2}{|c|}{ Total group $(n=1152)$} & $66 \%(n=448)$ & & $59 \%(n=260)$ & \\
\hline \multicolumn{6}{|c|}{ Univariate analyses } \\
\hline \multirow[t]{4}{*}{ Ethnicity } & $\operatorname{Dutch}^{\mathrm{a}}(n=347)$ & $76 \%(n=163)$ & 1.00 & $55 \%(n=69)$ & 1.00 \\
\hline & Turkish $(n=258)$ & $58 \%(n=91)$ & $0.43(0.27-0.66)^{* *}$ & $65 \%(n=59)$ & $1.52(0.87-2.65)$ \\
\hline & Moroccan $(n=222)$ & $60 \%(n=81)$ & $0.48(0.30-0.76)^{*}$ & $56 \%(n=47)$ & $1.05(0.60-1.83)$ \\
\hline & Surinamese $(n=325)$ & $65 \%(n=113)$ & $0.57(0.37-0.89)^{*}$ & $60 \%(n=85)$ & $1.23(0.76-2.00)$ \\
\hline \multirow[t]{2}{*}{ Gender } & Male $^{a}(n=576)$ & $64 \%(n=218)$ & 1.00 & $55 \%(n=123)$ & 1.00 \\
\hline & Female $(n=576)$ & $68 \%(n=230)$ & $1.22(0.89-1.68)$ & $63 \%(n=137)$ & $1.40(0.96-2.05)$ \\
\hline \multirow[t]{6}{*}{ Age } & $35-45(n=161)$ & $63 \%(n=44)$ & $0.86(0.49-1.49)$ & $57 \%(n=50)$ & $0.75(0.44-1.28)$ \\
\hline & $45-50^{\mathrm{a}}(n=427)$ & $66 \%(n=166)$ & 1.00 & $64 \%(n=108)$ & 1.00 \\
\hline & $50-55(n=287)$ & $66 \%(n=117)$ & $1.00(0.67-1.51)$ & $54 \%(n=57)$ & $0.65(0.39-1.06)$ \\
\hline & $55-60(n=156)$ & $67 \%(n=66)$ & $1.04(0.64-1.72)$ & $51 \%(n=26)$ & $0.58(0.31-1.09)$ \\
\hline & $60-65(n=83)$ & $59 \%(n=34)$ & $0.72(0.40-1.29)$ & $55 \%(n=12)$ & $0.67(0.27-1.63)$ \\
\hline & $65+(n=38)$ & $72 \%(n=21)$ & $1.33(0.57-3.13)$ & $78 \%(n=7)$ & $1.94(0.39-9.66)$ \\
\hline \multirow[t]{3}{*}{ GP practice } & $\operatorname{Dutch}^{\mathrm{a}}(n=295)$ & $79 \%(n=141)$ & 1.00 & $51 \%(n=57)$ & 1.00 \\
\hline & $\operatorname{Mix}(n=159)$ & $72 \%(n=76)$ & $0.71(0.40-1.23)$ & $55 \%(n=27)$ & $1.16(0.59-2.28)$ \\
\hline & Non-Western $(n=698)$ & $58 \%(n=231)$ & $0.38(0.25-0.57)^{* *}$ & $62 \%(n=176)$ & $1.56(1.00-2.43)^{*}$ \\
\hline \multirow[t]{4}{*}{ SES score } & $>0^{\mathrm{a}}(n=364)$ & $70 \%(n=152)$ & 1.00 & $54 \%(n=74)$ & 1.00 \\
\hline & 0 till $-2(n=268)$ & $71 \%(n=113)$ & $1.03(0.66-1.61)$ & $56 \%(n=59)$ & $1.07(0.64-1.78)$ \\
\hline & -2 till $-4(n=169)$ & $71 \%(n=74)$ & $1.06(0.63-1.76)$ & $63 \%(n=36)$ & $1.46(0.77-2.75)$ \\
\hline & $<-4(n=351)$ & $55 \%(n=109)$ & $0.51(0.34-0.77)^{* *}$ & $64 \%(n=91)$ & $1.49(0.92-2.40)$ \\
\hline \multicolumn{6}{|c|}{ Multivariate analyses } \\
\hline \multirow[t]{4}{*}{ Ethnicity } & $\operatorname{Dutch}^{\mathrm{b}}(n=347)$ & $76 \%(n=163)$ & 1.00 & $55 \%(n=69)$ & 1.00 \\
\hline & Turkish $(n=258)$ & $58 \%(n=91)$ & $0.94(0.50-1.76)$ & $65 \%(n=59)$ & $1.09(0.53-2.22)$ \\
\hline & Moroccan $(n=222)$ & $60 \%(n=81)$ & $0.71(0.41-1.23)$ & $56 \%(n=47)$ & $0.93(0.52-1.66)$ \\
\hline & Surinamese $(n=325)$ & $65 \%(n=113)$ & $1.31(0.69-2.49)$ & $60 \%(n=85)$ & $0.88(0.45-1.71)$ \\
\hline
\end{tabular}

${ }^{a}$ Reference category univariate analyses

${ }^{\mathrm{b}}$ Reference category multivariate analyses, corrected for relevant variables (ethnic mix of GP practice and/or SES score) ${ }^{*} p<0.05$

${ }^{* *} p<0.001$

to invite a person to participate in the HRA and to complete the HRA. The feasibility of this invitation step in the GP practice needs to be studied further. Finally, the number of GP practices was small because we aimed to recruit practices consisting mainly of specific underserved populations. Therefore, it was impossible to perform multi-level analyses. Theoretically, many practice-level characteristics could influence response and participation, therefore, our conclusions on the effect of practice on outcome measures should be regarded as a first indication and need to be studied further.

\section{Comparison with other studies}

Our postal HRA participation rate was lower compared to the general population [31-33]. This may, in part, be due to the low percentage of underserved populations in other studies and their use of an additional online HRA. Moreover, in these studies HRA results could not be calculated by patients themselves, returning the HRA might have worked as an incentive. In contrast, a pilot study of the Dutch cardiometabolic health check provided the risk score immediately and found similar participation rates as we did [34].

The telephone invitation increased the number of people making a decision about participation. This is in line with a study among non-participants in cardiovascular screening in which $40 \%$ changed their initial decision after receiving additional information about risks and screening [35].

The literature suggests that, if used as a separate strategy, face-to-face strategies are more effective in reaching underserved populations. We found that if used as an 
Table 5 HRA risk score and participation in PC

\begin{tabular}{|c|c|c|c|c|c|}
\hline & & \multicolumn{2}{|l|}{ HRA risk score } & \multicolumn{2}{|c|}{ Participation in $\mathrm{PC}^{\mathrm{a}}$} \\
\hline & & High & Odds ratio $(95 \% \mathrm{Cl})$ & Yes & Odds ratio $(95 \% \mathrm{Cl})$ \\
\hline \multicolumn{2}{|c|}{ Total group $(n=714)$} & $29 \%(n=207)$ & & $59 \%(n=123)$ & \\
\hline \multicolumn{6}{|c|}{ Univariate analyses } \\
\hline \multirow[t]{4}{*}{ Ethnicity } & $\operatorname{Dutch}^{c}(n=232)$ & $35 \%(n=82)$ & 1.00 & $46 \%(n=38)$ & 1.00 \\
\hline & Turkish $(n=150)$ & $37 \%(n=56)$ & $1.09(0.71-1.67)$ & $68 \%(n=38)$ & $2.44(1.20-4.97)^{*}$ \\
\hline & Moroccan $(n=132)$ & $30 \%(n=40)$ & $0.80(0.50-1.26)$ & $68 \%(n=27)$ & $2.41(1.09-5.31)^{*}$ \\
\hline & Surinamese $(n=200)$ & $15 \%(n=29)$ & $0.31(0.19-0.50)^{* *}$ & $69 \%(n=20)$ & $2.57(1.05-6.32)^{*}$ \\
\hline \multirow[t]{2}{*}{ Gender } & Male $^{c}(n=344)$ & $38 \%(n=130)$ & 1.00 & $63 \%(n=82)$ & 1.00 \\
\hline & Female $(n=370)$ & $21 \%(n=77)$ & $0.43(0.31-0.60)^{* *}$ & $53 \%(n=41)$ & $0.67(0.38-1.18)$ \\
\hline \multirow[t]{6}{*}{ Age } & $35-45(n=95)$ & $2 \%(n=2)$ & $0.14(0.03-0.61)^{*}$ & $0 \%(n=0)$ & - \\
\hline & $45-50^{\complement}(n=277)$ & $13 \%(n=36)$ & 1.00 & $67 \%(n=24)$ & 1.00 \\
\hline & $50-55(n=174)$ & $28 \%(n=48)$ & $2.55(1.57-4.13)^{* *}$ & $69 \%(n=33)$ & $0.91(0.36-2.29)$ \\
\hline & $55-60(n=93)$ & $55 \%(n=51)$ & $8.13(4.75-13.92)^{* *}$ & $53 \%(n=27)$ & $0.51(0.23-1.16)$ \\
\hline & $60-65(n=47)$ & $91 \%(n=43)$ & $71.97(24.37-212.50)^{* *}$ & $58 \%(n=25)$ & $0.63(0.27-1.49)$ \\
\hline & $65+(n=28)$ & $96 \%(n=27)$ & $180.75(23.82-1371.33)^{* *}$ & $52 \%(n=14)$ & $0.49(0.19-1.29)$ \\
\hline \multirow[t]{3}{*}{ GP practice ${ }^{b}$} & $\operatorname{Dutch}^{c}(n=198)$ & $31 \%(n=62)$ & 1.00 & $53 \%(n=33)$ & 1.00 \\
\hline & $\operatorname{Mix}(n=103)$ & $37 \%(n=38)$ & $1.28(0.78-2.12)$ & $50 \%(n=19)$ & $0.88(0.39-1.97)$ \\
\hline & Non-Western $(n=413)$ & $26 \%(n=107)$ & $0.77(0.53-1.11)$ & $66 \%(n=71)$ & $1.73(0.91-3.29)$ \\
\hline \multirow[t]{4}{*}{ SES score } & $>0^{c}(n=227)$ & $29 \%(n=65)$ & 1.00 & $55 \%(n=36)$ & 1.00 \\
\hline & 0 till $-2(n=173)$ & $32 \%(n=56)$ & $1.19(0.78-1.83)$ & $55 \%(n=31)$ & $1.00(0.49-2.05)$ \\
\hline & -2 till $-4(n=112)$ & $31 \%(n=35)$ & $1.13(0.69-1.85)$ & $60 \%(n=21)$ & $1.21(0.52-2.78)$ \\
\hline & $<-4(n=202)$ & $25 \%(n=51)$ & $0.84(0.55-1.29)$ & $69 \%(n=35)$ & $1.76(0.82-3.80)$ \\
\hline \multicolumn{6}{|c|}{ Multivariate analyses } \\
\hline \multirow[t]{4}{*}{ Ethnicity } & $\operatorname{Dutch}^{d}(n=232)$ & $35 \%(n=82)$ & 1.00 & NA & NA \\
\hline & Turkish $(n=150)$ & $37 \%(n=56)$ & $1.59(0.93-2.70)$ & NA & NA \\
\hline & Moroccan $(n=132)$ & $30 \%(n=40)$ & $0.92(0.52-1.63)$ & NA & NA \\
\hline & Surinamese $(n=200)$ & $15 \%(n=29)$ & $0.54(0.28-1.01)$ & NA & NA \\
\hline
\end{tabular}

NA Not applicable

${ }^{a}$ As percentage of individuals with a high HRA risk score

${ }^{b}$ Predominant composition of patient population

'Reference category univariate analyses

${ }^{d}$ Reference category multivariate analyses, corrected for relevant variables (gender, age)

${ }^{*} p<0.05$

${ }^{* *} p<0.001$

additional step in a multi-step strategy, the added value of the face-to-face invitation was negligible. We also saw that the individuals left over for face-to-face recruitment were more often the 'harder-to-reach' men and individuals with a low SES. Additionally, face-to-face strategies are labour-intensive and expensive. Given their lack of feasibility in practice and the high response obtained using a postal and telephone invitation, this latter multi-step approach seems advisable $[16,17]$.

Ethnic differences in response and HRA participation were no longer significant when adjusting for ethnic mix of GP practice, possibly because of differences in practice size or sociocultural aspects (e.g., stronger assimilation and social cohesion in some neighbourhoods). The predominantly
non-Western practices had the lowest response and participation rates. These practices were larger and located in more deprived neighbourhoods where social cohesion is usually lower and both native Dutch and non-Western patients may be more illiterate [36]. Unfortunately, we did not have individual SES scores. We did, however, have individual education information for a sample of participants. Using this data did not change our conclusions, justifying the use of a neighbourhood SES score.

The PC participation rate among our high-risk patients was larger than in the pilot study among the general population, but smaller than in two other studies of the Dutch cardiometabolic health check [31, 32, 34]. In the latter studies, high-risk participants were invited for the 
PC, whereas in both the pilot and our study, high-risk participants were personally responsible for scheduling an appointment. In follow-up interviews, high-risk participants who had not attended the PC frequently indicated that they had not been aware or had not understood they had to schedule their own appointment. Thus, it would be advisable for these groups to shift the responsibility of making an appointment to the GP.

Our PC participation rate was larger than in the British NHS health check [7, 11]. However, their patients were risk-stratified in advance, and only high-risk individuals were invited. We risk-stratified by means of the HRA. High-risk HRA participants were more likely to also participate in the PC.

The lower age threshold for being invited explained the lower HRA risk score among Surinamese. This emphasizes that a lower threshold is only useful when an ethnicity-based risk score is used [37].

The native Dutch with a low SES refrained most often from PC participation. These groups have been shown to rely less on the GP for lifestyle advice [38].

\section{Conclusions}

\section{Principal findings}

Total response was as high as $70 \%$ among our underserved populations using a funnelled invitation design. Of the responders, $62 \%$ participated in the HRA. Postal response was $41 \%$, of whom $66 \%$ participated. Telephone response was $46 \%$ among postal non-responders, of whom $59 \%$ participated in the HRA. A face-to-face invitation barely increased response and HRA participation rates. Of the highrisk individuals, 59 \% participated in the PC, irrespective of invitation step.

\section{Implications and future research}

Underserved populations can be reached by a low-cost culturally adapted postal approach with a reminder and follow-up telephone calls. The actual cost-effectiveness of this approach needs to be studied. Efforts should be particularly targeted at GP practices in the most deprived areas, focusing on why response and participation fall behind less deprived but still low socioeconomic areas. Future qualitative (ethnographic) studies could be useful. Though a face-to-face approach barely increased response and participation, in The Netherlands, only this 'case-finding' approach is currently reimbursed by basic health insurance [18]. Considering the socioeconomic inequalities in health, the feasibility of implementing a culturally adapted two-step invitation strategy to increase participation in the HRA should be discussed and studied. Moreover, to increase the likelihood of cost-effectiveness of two-stage screening, as many high-risk individuals as possible need to comply with attending their GP for further testing. If feasible, the responsibility for scheduling an appointment should be shifted toward the GP practice or other healthcare organisations.

\section{Additional files}

Additional file 1: Exclusion criteria. Detailed list of exclusion criteria
for study participation. (DOCX $15 \mathrm{~kb}$ )

Additional file 2: (Cultural) Adaptations to invitation, HRA, and information brochure. Detailed list of (cultural) adaptations made to invitation, HRA, and information brochure. (DOCX 1971 kb)

\section{Abbreviations}

CMD: Cardiometabolic disease; CVD: Cardiovascular disease; DM: Diabetes mellitus; GP: General practitioner; HRA: Health risk assessment; OR: Odds ratio; PC: Prevention consultation; SES: Socioeconomic status.

\section{Competing interests}

The authors declare that they have no competing interests.

\section{Authors' contributions}

MC, SD, WG, and AS filed the proposal for this study. The design, execution, and analysis were mainly done by IG and MC, in close collaboration with the research team. All authors had full access to all of the data in the study and can take responsibility for the integrity of the data and the accuracy of the data analysis. IG is guarantor. All authors read and approved the final manuscript.

\section{Acknowledgements}

The authors thank all GP practices for their cooperation in conducting the study at their locations, and the patients in particular for their participation.

This study was funded by the Dutch Heart foundation, the Dutch Diabetes Foundation, and the Dutch Kidney foundation in a collaboration called LekkerLangLeven [Living nice and long]. The views presented in this manuscript are those of the authors and do not necessarily reflect those of the study funders.

\section{Ethical approval}

This study was approved by the Medical Ethical Committee of Leiden University Medical Center (P11.151).

\section{Transparency}

The lead author (IG) affirms that the manuscript is an honest, accurate, and transparent account of the study being reported; that no important aspects of the study have been omitted; and that any discrepancies from the study as planned have been explained.

\section{Author details}

${ }^{1}$ Department of Public Health and Primary Care, Leiden University Medical Center, Hippocratespad 21, PO Box 9600, V0-P, 2300 RC, Leiden, The Netherlands. ${ }^{2}$ Department of Primary and Community Care, Radboud University Medical Center, Nijmegen, The Netherlands. ${ }^{3}$ Department of Medical Decision Making, Leiden University Medical Center, 2300RC, Leiden, The Netherlands.

Received: 23 March 2015 Accepted: 11 August 2015

Published online: 03 September 2015

\section{References}

1. World Health Organization (WHO). Fact sheet number 310: the top ten causes of death. 2008.

2. Mackenbach JP, Stirbu I, Roskam AJ, Schaap MM, Menvielle G, Leinsalu M, et al. Socioeconomic inequalities in health in 22 European countries. N Engl J Med. 2008;358(23):2468-81.

3. Mackenbach JP, Kunst AE, Cavelaars AE, Groenhof F, Geurts JJ. Socioeconomic inequalities in morbidity and mortality in western Europe. The EU Working Group on Socioeconomic Inequalities in Health. Lancet. 1997;349(9066):1655-9.

4. Bos V, Kunst AE, Keij-Deerenberg IM, Garssen J, Mackenbach JP. Ethnic inequalities in age- and cause-specific mortality in The Netherlands. Int J Epidemiol. 2004;33(5):1112-9. 
5. Dijkshoorn H, Uitenbroek DG, Middelkoop BJ. Prevalentie van diabetes mellitus en hart- en vaatziekten onder Turkse, Marokkaanse en autochtone Nederlanders [Prevalence of diabetes mellitus and cardiovascular disease among immigrants from Turkey and Morocco and the indigenous Dutch population]. Ned Tijdschr Geneeskd. 2003;147(28):1362-6.

6. Kunst $A E$, Mackenbach JP, Lamkaddem M, Rademakers J, Devillé W. Overzicht en evaluatie van resultaten van wetenschappelijk onderzoek naar etnische verschillen in gezondheid, gezondheidsrisico's en zorggebruik in Nederland, [Overview and evaluation of results from scientific research on ethnic differences in health, health risks, and health care use in the Netherlands]. Utrecht, the Netherlands: Nederlands instituut voor onderzoek van de gezondheidszorg (NIVEL); 2008.

7. Dalton AR, Bottle A, Okoro C, Majeed A, Millett C. Uptake of the NHS Health Checks programme in a deprived, culturally diverse setting: cross-sectional study. J Public Health (Oxf). 2011;33(3):422-9.

8. Brunner-Ziegler S, Rieder A, Stein KV, Koppensteiner R, Hoffmann K, Dorner TE. Predictors of participation in preventive health examinations in Austria. BMC Public Health. 2013;13:1138.

9. Amoroso C, Harris MF, Ampt A, Laws RA, McKenzie S, Williams AM, et al. The 45 year old health check - feasibility and impact on practices and patient behaviour. Aust Fam Physician. 2009;38(5):358-62.

10. Dryden R, Williams B, McCowan C, Themessl-Huber M. What do we know about who does and does not attend general health check? Findings from a narrative scoping review. BMC Public Health. 2012;12:723.

11. Cochrane T, Gidlow CJ, Kumar J, Mawby Y, labal Z, Chambers RM. Cross-sectional review of the response and treatment uptake from the NHS Health Checks programme in Stoke on Trent. J Public Health (Oxf). 2013;35(1):92-8.

12. Khunti K, Gillies CL, Taub NA, Mostafa SA, Hiles SL, Abrams KR, et al. A comparison of cost per case detected of screening strategies for Type 2 diabetes and impaired glucose regulation: modelling study. Diabetes Res Clin Pract. 2012:97(3):505-13.

13. Hardy RE, Ahmed NU, Hargreaves MK, Semenya KA, Wu L, Belay Y, et al. Difficulty in reaching low-income women for screening mammography. J Health Care Poor Underserved. 2000;11(1):45-57.

14. Camilloni L, Ferroni E, Cendales BJ, Pezzarossi A, Furnari G, Borgia P, et al. Methods to increase participation in organised screening programs: a systematic review. BMC Public Health. 2013;13:464.

15. Segura JM, Castells X, Casamitjana M, Macia F, Porta M, Katz SJ. A randomized controlled trial comparing three invitation strategies in a breast cancer screening program. Prev Med. 2001;33(4):325-32.

16. Thorogood M, Coulter A, Jones L, Yudkin P, Muir J, Mant D. Factors affecting response to an invitation to attend for a health check. J Epidemiol Community Health. 1993:47(3):224-8.

17. Bonfill X, Marzo M, Pladevall M, Marti J, Emparanza Jl. Strategies for increasing women participation in community breast cancer screening. Cochrane Database Syst Rev. 2001;1:CD002943.

18. Wyers C, Evers SMAA, Ruwaard D. Rapport Ex-ante kosteneffectiviteitsanalyse van het PreventieConsult Cardiometabool risico [Report Ex-ante cost-effectiveness of the Prevention Consultation Cardiometabolic Risk]. Maastricht, the Netherlands: Maastricht University, Faculty of Health, Medicine, and Life Sciences. CAPHRI, School for Public Health and Primary Care, Department of Health Services Research; 2013.

19. Pandya A, Weinstein MC, Salomon JA, Cutler D, Gaziano TA. Who needs laboratories and who needs statins?: Comparative and cost-effectiveness analyses of non-laboratory-based, laboratory-based, and staged primary cardiovascular disease screening guidelines. Circ Cardiovasc Qual Outcomes. 2014;7(1):25-32

20. Conroy RM, Pyorala K, Fitzgerald AP, Sans S, Menotti A, de Backer G, et al. Estimation of ten-year risk of fatal cardiovascular disease in Europe: the SCORE project. Eur Heart J. 2003;24(11):987-1003.

21. Lindstrom J, Tuomilehto J. The diabetes risk score: a practical tool to predict type 2 diabetes risk. Diabetes Care. 2003;26(3):725-31.

22. Assendelft WJ, Nielen MM, Hettinga DM, van der Meer V, van Vliet M, Drenthen AJ, et al. Bridging the gap between public health and primary care in prevention of cardiometabolic diseases; background of and experiences with the Prevention Consultation in The Netherlands. Fam Pract. 2012;29(Suppl 1):i126-31.

23. Sociaal en Cultureel Planbureau [Social and Cultural Planning Office] Status scores. 2014.
24. Baker D, Mead N, Campbell S. Inequalities in morbidity and consulting behaviour for socially vulnerable groups. Br J Gen Pract. 2002;52(475):124-30.

25. Scaife B, Gill P, Heywood P, Neal R. Socio-economic characteristics of adult frequent attenders in general practice: secondary analysis of data. Fam Pract. 2000;17(4):298-304.

26. NHG standaard [Guideline for Dutch GPs]. Cardiovasculair risicomanagement (Tweede herziening) [Cardiovascular risk management (Second revision)] Huisarts Wet. 2012;55(1):14-28.

27. Groenenberg I, Crone MR, van Dijk S, Gebhardt WA, Ben Meftah J, Middelkoop BJ, et al. 'Check it out!' Decision-making of vulnerable groups about participation in a two-stage cardiometabolic health check: a qualitative study. Patient Educ Couns. 2015;98(2):234-44. doi:10.1016/ j.pec.2014.10.010

28. Cooke R, French DP. How well do the theory of reasoned action and theory of planned behaviour predict intentions and attendance at screening programmes? A meta-analysis. Psychology and Health. 2008;23(7):745-65.

29. Biesecker BB, Schwartz MD, Marteau TM. Enhancing informed choice to undergo health screening: a systematic review. Am J Health Behav. 2013;37(3):351-9.

30. Groenenberg I, Crone MR, van Dijk S, Gebhardt WA, Ben MJ, Middelkoop BJ, et al. 'Check it out!' Decision-making of vulnerable groups about participation in a two-stage cardiometabolic health check: a qualitative study. Patient Educ Couns. 2015;98(2):234-44.

31. Kerkhof van de R, Wouda PJ, Vening RA, Dinant GJ, Spigt MG. Cardiometabole risicofactoren opgespoord met preventieconsult. Nederlands Tijdschrift voor Geneeskunde. 2010;154:A1860.

32. Klomp M, Meulepas M, Anema B, Harms L. PreventieConsult in praktijk: een pilot. Medisch Contact. 2011;66(11):659-61

33. Vermunt PW, Milder IE, Wielaard F, van Oers JA, Westert GP. An active strategy to identify individuals eligible for type 2 diabetes prevention by lifestyle intervention in Dutch primary care: the APHRODITE study. Fam Pract. 2010:27(3):312-9.

34. Nielen MMJ, van der Meer V, Assendelft WJJ, Schellevis FG. Eerste ervaringen met het PreventieConsult Cardiometabool risico. Huisarts en Wetenschap. 2011;54(8):414-9.

35. Sogaard R, Lindholt J, Gyrd-Hansen D. Individual decision making in relation to participation in cardiovascular screening: a study of revealed and stated preferences. Scand J Public Health. 2013:41(1):43-50.

36. Becares L, Stafford M, Laurence J, Nazroo J. Composition, concentration and deprivation: exploring their association with social cohesion among different ethnic groups in the UK. Urban Stud. 2011;48(13):2771-87.

37. Bindraban NR, van Valkengoed IG, Mairuhu G, Holleman F, Hoekstra JB, Michels BP, et al. Prevalence of diabetes mellitus and the performance of a risk score among Hindustani Surinamese, African Surinamese and ethnic Dutch: a cross-sectional population-based study. BMC Public Health. 2008;8:271.

38. Bach Nielsen KD, Dyhr L, Lauritzen T, Malterud K. Long-term impact of elevated cardiovascular risk detected by screening. A qualitative interview study. Scand J Prim Health Care. 2005;23(4):233-8.

\section{Submit your next manuscript to BioMed Central and take full advantage of:}

- Convenient online submission

- Thorough peer review

- No space constraints or color figure charges

- Immediate publication on acceptance

- Inclusion in PubMed, CAS, Scopus and Google Scholar

- Research which is freely available for redistribution 